\title{
Obesity: Modulating Adiponectin Levels Through Diet
}

\author{
Luciana França Matoso Barbalho ${ }^{1}$, Virna Ferreira de Souza ${ }^{1}$, Juliana Luciano Gaspar Capibaribe ${ }^{1}$, Thalita \\ Marjorie Cavalcante de Azevedo ${ }^{1}$, Kétsia Bezerra Medeiros ${ }^{2}$ and Alexandre Coelho Serquiz*3 \\ ${ }^{1}$ Graduation of the Nutrition Course, Brazil
}

${ }^{2}$ Master Professor of the Nutrition Course, Brazil

${ }^{3}$ Professor of the Nutrition Course, Brazil

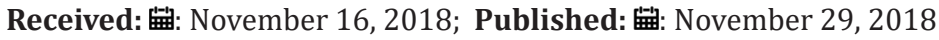

*Corresponding author: Alexandre Coelho Serquiz, Professor of the Nutrition Course, RN, Brazil

\section{Mini Review}

Obesity is considered a chronic condition of multiple etiology that can be linked to several factors, such as behavior, metabolism, genetics, environment, and psychosocial aspects. It is characterized by the excess of body fat from the excessive consumption of calories combined with a lack of physical activity. The excessive body fat causes a state of chronic inflammation that can lead to the development of chronic non-communicable diseases, among which the most common are diabetes mellitus, cardiovascular diseases, and cancer. According to the World Health Organization (WHO), "obesity is considered a global epidemic caused, primarily, by dietary and physical activity patterns." Such a scenario is directly related to the nutritional transition which occurred in the last decades - the dietary replacement of natural foods with processed and ultra-processed foods with a predominance of excessive salt, fat, and sugars. This new diet, with a higher energy density, combined with the lack of physical activity culminated in this everincreasing epidemic that became a global public health problem.

In the past, the adipose tissue was only the primary source of unlimited energy in the body. However, over the past few years, studies have shown that the organ is responsible for a vital endocrine function in the production of several peptides involved in metabolic processes. These substances are called adipokines and can have either an anti-inflammatory or pro-inflammatory nature. Adiponectin and Interleukin-10 are examples of anti-inflammatory adipokines, whereas TNF- $\alpha$, NF- $\kappa \beta$, and leptin are considered pro-inflammatory. Individuals in a nutritional state of obesity with chronic inflammation have an increased synthesis of proinflammatory adipokines, which inhibit the synthesis of adiponectin. That is why obesity is considered to have a negative correlation with adiponectin and a positive one with pro-inflammatory adipokines. Adiponectin, as an anti-inflammatory adipokine, plays an essential part in combating obesity and helping patients with diabetes, since it reduces insulin resistance. Marreiro [1] considers the increase of insulin sensitivity to be the consequence of its ability to activate the AMPK (AMP-activated protein kinase) in the muscles and liver through the interaction with its receivers in the cell membrane, which would inhibit gluconeogenesis and increase the oxidation of fatty acids and the glucose uptake in the muscles. The literature shows that some functional foods are effective in increasing adiponectin levels and, consequently, improving the quality of life of individuals, as shown in the (Table 1).

Table 1: List of studies researched.

\begin{tabular}{|c|c|c|c|}
\hline Authors & Year & Title & $\begin{array}{c}\text { Food } \\
\text { Mentioned }\end{array}$ \\
\hline Kabiri et al. & 2016 & $\begin{array}{l}\text { Impact of olive oil-rich diet on } \\
\text { serum omentin and adiponectin } \\
\text { levels: a randomized cross-over } \\
\text { clinical trial among overweight } \\
\text { women }\end{array}$ & Olive oil \\
\hline $\begin{array}{l}\text { Zhang Yi; } \\
\text { Zhang DZ }\end{array}$ & 2018 & $\begin{array}{l}\text { Associations of coffee } \\
\text { consumption with circulating level } \\
\text { of adiponectin and leptin. A meta- } \\
\text { analysis of observational studies }\end{array}$ & Coffee \\
\hline Bradford PG & 2013 & Curcumin and Obesity & Turmeric \\
\hline Ngatu RN & 2017 & $\begin{array}{c}\text { Uncovering adiponectin } \\
\text { Replenishing property of } \\
\text { sujiaonori algal biomaterial in } \\
\text { humans }\end{array}$ & $\begin{array}{l}\text { Sujiaonori } \\
\text { algae }\end{array}$ \\
\hline
\end{tabular}

Studies show that the use of curcumin supplements (a polyphenol found in turmeric) in individuals with type 2 diabetes is linked to an increase in adiponectin levels and a decrease of the inflammatory processes mediated by TNF- $\alpha$. Like $\beta$-carotene, olive oil and coffee are also positively associated with an increase in the 
circulating levels of adiponectin. $\beta$-carotene has a favorable effect on insulin sensitivity in obese individuals, whether directly or through its pro-vitamin A action, which creates possibilities of dietary strategies for the prevention of metabolic syndrome. Another food that has been studied witch positive effects is the Sujiaonori algae (Enteromorpha Prolifera Muller), found in the Shimanto River in the city of Kochi, Japan. Researchers have investigated it through dietary interventions as a food that would induce the increase in adiponectin production, being effective in reducing hypertension, especially the systolic blood pressure, and the Body Mass Index (BMI) [2]. It is a biomaterial rich in fiber that contains polyphenols, bioactive compounds, vitamins, and polyunsaturated fatty acids with antioxidant and anti-inflammatory properties capable of stimulating the immune system. Adiponectin has anti-atherogenic properties by inhibiting TNF- $\alpha$ and NF-k $\beta$. Its increase in plasma concentrations is associated with the reduction of myocardial infarction and the capacity of regulating the secretion of proinflammatory cytokines [3]. Its anti-inflammatory effects can be enhanced by the fact that the adiponectin reduces the production of IL-10 and stimulates an agonist to the IL-1 receptor (Figure 1). The consumption of functional foods is an option that should be considered for obese individuals since it can increase the levels of anti-inflammatory adipokines and reduce the inflammatory effects caused by the excess of adipose tissue [4]. Although the studies found did not include long-term interventions, and there are many factors that still need to be considered, in addition to several mechanisms that need to be clarified, the effectiveness of including those foods in the diet has shown their considerable modulating potential with evident positive effects.

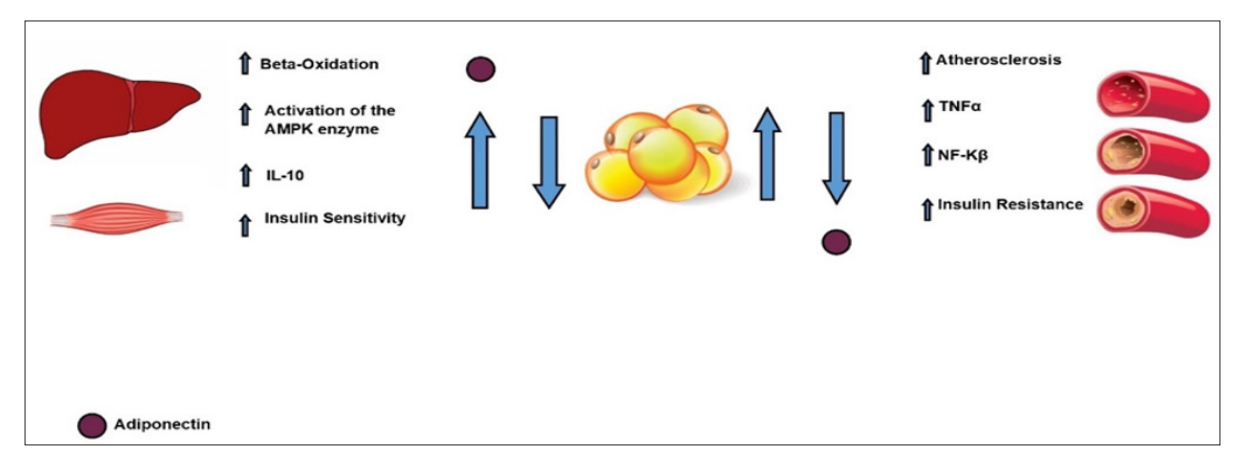

Figure 1: Increase of adipose tissue is inversely proportional to the levels of adiponectin in obese individuals, thus, the greater the accumulation of adipose tissue, the lower the adiponectin levels. Studies indicate that the increase of this anti-inflammatory cytokine would aid in lipid beta-oxidation, activation of the AMPK enzyme, increase in IL-10 and insulin sensitivity. Otherwise, its fall would be associated with atherosclerosis, increased pro-inflammatory cytokines such as TNF- $\alpha$ and NF-K $\beta$, as well as insulin resistance.

\section{References}

1. Marreiro, DDN Obesidade, Cozzolino SMF, Cominetti C (2013) Bases Bioquímicase Fisiológicas Da Nutrição. São Paulo: Manole pp. 912-933.

2. Zhang Yi, Dian Zhong (2018) Associations of coffee consumption with circulating level of adiponectin and leptin. A meta-analysis of observational studies. International journal of food sciences and nutrition 69(8): 1003-1012.

ISSN: 2574-1241

DOI: 10.26717/BJSTR.2018.11.002117

Alexandre Coelho Serquiz. Biomed J Sci \& Tech Res

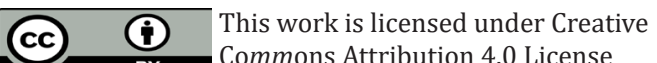

Submission Link: https://biomedres.us/submit-manuscript.php
3. Kabiri Akram (2017) Impact of olive oil-rich diet on serum omentin and adiponectin levels: A randomized cross-over clinical trial among overweight women. International journal of food sciences and nutrition 68(5): 560-568.

4. Peter G Bradford (2013) Curcumin and obesity. Bio factors 39(1): 78-87. 